\title{
Práctica y teorización de una pedagogía intercultural en nuestramerica
}

Entrevista a Jorge Alejandro Santos

Profesor de la Facultad de Filosofía de la Universidad de Buenos Aires Posdoctorando por la Universidad Comunitaria de la Región de Chapecó, Santa Catarina, Brasil

\section{Por:}

Jose Daniel Fonseca-Sandoval

Universidad ICESI jfonsandoval@hotmail.com

Entrevista recibida el 05/05/2018 y aprobado el 18/07/2018

Cómo citar este artículo:

Fonseca Sandoval, J. (2018). Práctica y teorización de una pedagogía intercultural en nuestramerica.Trans-Pasando Fronteras, (12). 


\section{En Trans-pasando Fronteras creemos necesario e impor- tante pensar, actuar y dialogar desde un lugar de enunciación, es decir asumir y valorar la posición y el espacio desde el cual se plantean y exponen las ideas. En este sentido, ¿cuéntenos quién es Jorge Santos pedagogo, investigador y filósofo?}

Yo soy egresado de la UBA, soy de un pueblo del Norte de la Argentina, con una trayectoria casi completa en la UBA: obtuve mi título de grado y de máster en la misma institución. Pero yo soy del interior, y empecé una carrera típica de las personas de la periferia, limitadas a dos o tres posibilidades, más en una época en la que no había internet. Empecé a los dieciocho años y ahora tengo cuarenta y dos; hace 24 años era muy diferente, pero siempre tuve una gran vocación por estudiar, y durante la carrera de derecho me empecé a interesar por los aspectos filosóficos y pedagógicos. No obstante, trabajé como abogado en cuanto me recibí, mientras terminaba la carrera de filosofía. Debido a que entonces se vivió una crisis económica, tuve que dedicarme a ello. Ya luego, pude dedicarme al ámbito filosófico y científico. Pero en mi época de estudiante trabajé en sectores populares de la ciudad de Buenos Aires, que aquí se denominan como "Villas Miseria". Comparten algunos rasgos con otras periferias como las favelas en Brasil, en las que se ubican migrantes internos o de países limítrofes, que se ubican en el rededor de las grandes ciudades. En estas comunidades hay muchas necesidades, por lo que estuve trabajando allí en proyectos de alfabetización y reconocimiento de derechos. Tiempo después entendí algo mejor la ciudad y me especialicé un poco más en los temas que me interesaban, como el tránsito de comunidades indígenas en el sector urbano y la filosofía intercultural.

Después de trabajar como abogado durante cinco años, me gané una beca para hacer el Doctorado en Filosofía, el cual enfo- 
qué en temas de educación intercultural a partir del trabajo que había realizado antes. Ahora estoy haciendo un Posdoctorado en Brasil, trabajando con un grupo étnico en la formación de profesores indígenas para la educación de los miembros de la comunidad. Por fortuna, he encontrado la forma de aplicar mi tesis doctoral a través de este proyecto, lo cual suele ser un problema para los académicos en ciencias sociales.

Por otra parte, soy profesor de la Universidad de Buenos Aires, en la Facultad de Filosofía, en el programa de Maestría en Estudios Culturales Latinoamericanos, en las clases de Pensamiento Latinoamericano 1 y 2. No obstante, también pertenezco al seminario-grupo Decolonia, que trabaja la perspectiva de decolonial, intercultural y latinoamericana en derecho y ciencias sociales.

\section{Las ciencias sociales son consideradas residuales y margi- nales en los currículos y programas académicos universita- rios, incluso en áreas aparentemente humanísticas como el derecho, la ciencia política y la economía. ¿Qué razones cree que pueden explicar esta precarización de las reflexiones socio- culturales en la formación académica?}

Lo que sucede con programas como el de derecho o economía, es que los miran desde una perspectiva técnica profesionalizante, en la que tratan que sean lo más semejantes posibles a las ciencias naturales o exactas. Con los avances tecnológicos sucede algo curioso, pues se ven desde una mirada tecnocrática de derecha que ha impedido que las teorías sociales puedan ver la comunicación a través de internet y videollamadas como un fenómeno socio-cultural complejo. No obstante, nuestra responsabilidad como científicos sociales también radica en abordar esta temática sin miedo; 
porque tenemos cierta resistencia a entrar en estos avances tecnológicos, a pesar de que escribimos en Word y nos comunicamos a través de videollamadas. Tenemos el deber de abordar estas tecnologías, con una mirada crítica. La ubicación de las ciencias sociales como anticuadas tiene que ver con eso, con que hay temáticas que los científicos sociales resisten, por considerarlas técnicas y tecnocráticas. Yo creo que ahí nos agarraron un poco en off-side. En mi página web, por ejemplo, estamos haciendo el trabajo de traducción del contenido a cuatro lenguas, incluida la de la comunidad con la que trabajo en Brasil. Esto con el fin de difundir la cultura del sur de Brasil; los jóvenes indígenas de la comunidad tienen celulares, y a pesar de que la conexión sea mala, no encuentran contenido en su lengua. Entonces este es un terreno para avanzar, para que las ciencias sociales exploren y entiendan estos problemas.

\section{Ante este panorama de progresiva exclusión de las cien- cias sociales, ¿considera que lo anterior tiene alguna relación con las estructuras socioeconómicas de dominación?}

Actualmente hay un momento político y discurso fuerte, que acoge lo que se denomina como "law war" o guerra a través del derecho, que consiste en conseguir fines o intereses, a través de la ley, que hoy día difícilmente se pueden lograr por la fuerza. Las ciencias sociales también se ven marginadas por este tipo de discursos que tienden a opacar u ocultar las desigualdades sociales y gestionar la idea de una sociedad sin conflictos. Esto es posible en la medida que se utilizan los medios de comunicación y las tecnologías de la información. Un ejemplo es la segmentación de la información que se le entrega a los ciudadanos, con el propósito de que solo reciban la información afín a sus intereses y posiciones políticas. Las ciencias sociales, si bien tenemos un discurso crítico, 
tenemos que avanzar en la comprensión de estas temáticas. A veces nosotros tendemos a evitar esas fronteras de inmersión, mientras que del otro lado son muy prácticos; así nos cuesta salir del ámbito académico. Tenemos que tratar de llevar estas reflexiones a lo cotidiano; no solo tenemos que hacerlo, sino que es necesario.

4. Si pensamos a partir de lo que Enrique Dussel denomina como "la primera modernidad", establecida en el momento en que se produce la invención de América Latina (que usualmente se refiere como descubrimiento), el pensamiento científico y social de nuestra-américa ha estado atado a la centralidad de Europa como lugar de producción de saber universal. Cómo cree que esto ha incidido en la forma en que la academia del continente produce conocimiento y categorías de análisis. ¿Existe una continuidad en esta práctica o ha habido momentos de ruptura?

A mí me gusta citar acá a un pensador portugués, que es Boaventura de Sousa Santos, quien, al pensar las situaciones de colonialidad en varios terceros mundos, dice que en el lugar en el que más Europa hay, de esos terceros mundos, en América Latina. Si bien tenemos mucho de Europa, y escribimos y hablamos en una lengua ajena, no somos Europa. Esto es un problema propio de nuestra identidad. Tu sabes, por ejemplo, los argentinos tienden a creerse mucho eso de ser europeo. En África, las lenguas propias están más presentes que acá. En ese sentido, tenemos mucho de Europa, pero a la vez vivimos una relación conflictiva. La visión colonial de otros países sobre nosotros, y de nosotros mismos sobre nosotros mismos, es muy fuerte. Un ejemplo de algo de moda, como Netflix. Si vas a buscar algo que haga referencia a América Latina ¿qué te encuentras? Narcos, es lo primero que te 
arroja: somos todos narcos. Esto es una falsedad evidente, pero si lo miramos a la inversa, Europa y Estados Unidos componen el $60 \%$ del consumo global de drogas en el mundo. Y nadie dice que son todos drogadictos. El asunto es que cuando se mira al latinoamericano se dice que todos somos sucios, feos y malos, y narcos, cuando, en ese ejemplo, los países con esa visión hacen parte del $50 \%$ del problema del narcotráfico. Pero incluso nosotros, como te decía, nos vemos así: al vernos reflejados en esa pantalla colonial, reproducimos esos imaginarios, que obedecen a una cierta autoestima baja. Es cierto que hay mucho trabajo para hacer en este campo; la colonialidad está muy presente en toda la cultura latinoamericana. Hay una cierta masa crítica, integrada por entidades gubernamentales e intelectuales y grupos académicos enfocados en el tema. Pero aun así la continuidad de estos discursos es compleja: pasa con los indígenas, que reciben todos los apelativos negativos, de vagos, perezosos, aprovechados. Igual pasa con los latinoamericanos, como ya mencionamos. En las comunidades indígenas, por ejemplo, pasa algo llamativo: quienes tienen mayor acceso a la tecnología tienen una mejor posición que quienes guardan una vida más tradicional. Se viene como en cascada la colonialidad. Yo por eso creo que como la colonialidad se transmite por medio de los distintos avances tecnológicos, las ciencias sociales tienen que explorar ese terreno.

Cuando Lutero traduce la Biblia del latín al alemán, utilizaba como sinónimo traducción y germanización, en el sentido que cuando la apropiación cultural tiene que ver con la traducción al propio contexto cultural. Si eso siempre nos viene de afuera y no podemos apropiarlo y traducirlo, damos continuidad a la colonialidad. Siempre hay una cierta mitología sobre lo ajeno, como que no somos capaces de apropiarlo y de darle un sentido propio; cuando cambié de Linux a Windows, por poner un ejemplo, sentí que 
la computadora empezó a obedecerme y no al revés; el asunto es que antes de entender cómo funcionaba pensé que me tardaría dos años, y resultó que me tomó dos días. Eso es un pequeño acto de descolonización. Lo que se llama como filosofía de la liberación vendría siendo en este caso tecnología de la liberación.

\section{5. ¿El derecho puede ser un elemento de transformación so- cial o es simplemente un instrumento para la dominación?}

El derecho es un instrumento para organizar a la sociedad. En últimas lo que hace el derecho es reflejar una cierta situación de poder en una sociedad. En el sentido de que, como bien decíamos, hay unas situaciones ocultas de desigualdad de poder en donde es el derecho de los más poderosos el que anula el derecho de los más débiles. Sin embargo, esto no es muy evidente porque quien tiene poder no habla mal de sí mismo, la clase dominante no va a decir que se está aprovechando de ciertas personas. Como esto sería contrario a sus intereses, lo que hacen es expresar y constatar una igualdad formal ante la ley. Pero solamente la enunciación de igualdad abre ciertas posibilidades a grupos que dicen "somos iguales ante la ley", por ende "necesito encontrar un abogado" que aborde y haga valer esta declaración de igualdad. Entonces, si bien es cierto que el derecho consolida un sistema de dominación, siempre hay espacios en los que, si uno utiliza la retórica con habilidad, se pueden obtener resultados favorables a los oprimidos. Recientemente me compartieron un libro titulado "Las tácticas de poder de Jesucristo", en los que se aborda por qué un hijo de un carpintero hace tambalear a uno de los imperios más poderosos del momento. Lo que sucede es que, como me advirtió quien me recomendó el libro, hay que hacerlo bien para no terminar crucificado. 
Siempre hay estrategias que permiten atacar y modificar relaciones de poder hacia un orden social más justo. Creo que es preferible el orden al desorden: porque en el desorden triunfa el que tiene más fuerza, una especie de ley del más fuerte. Por eso le gustan las pocas regulaciones al neoliberalismo. Entonces, mi idea es que a partir del orden que estamos, transitemos a un orden social más justo.

\section{Respecto a la legitimidad de la acción política colectiva expresada en la protesta social, parece que en América La- tina se cumple lo que Dussel ha denominado como la ilegali- dad de la justicia y la legalidad de la injusticia, es decir, que se protegen normas o prácticas procedimentales injustas mientras que se censura por medio de la fuerza las mani- festaciones que propenden por la justicia social. ¿Cuál puede ser la relación o el vínculo entre la academia y los académicos con los movimientos sociales y populares?}

Mirá, en Brasil es un caso particular, porque a veces uno tiene una muy buena imagen de los académicos. Pero en Brasil, a Dilma Roussef la sacan del gobierno al imputarla de una acción que no resultó siendo un delito, lo cual deja a los injustos que promovieron el Impeachment -corruptos, investigados y algunos condenados- en una posición de poder frente a los justos. Algunos jueces, como Sergio Moro, también integran la academia legal en Brasil. Abogados y jueces alineados con estas injusticias legales, también son profesores y académicos. Entonces yo creo que hay que continuar ese vínculo con los movimientos sociales, pero no descuidar otros ámbitos de intervención, como es el caso del sistema judicial. También tenemos que formar profesionales críticos para la justicia o incluso para las empresas. Así las cosas, me parece fundamental el trabajo con movimientos sociales, pero no 
podemos descuidar otros escenarios de acción; el sistema judicial está mostrando su importancia en estos momentos de crisis de la legalidad de la injusticia en América Latina. Hay que animarse a dialogar con otros sectores, ámbitos y oficios, inmiscuirse y comprometerse, no hay que huirle a eso.

\section{Cuál es la relación que a partir de su práctica pedagógica e investigadora logra establecer entre una pedagogía de la "liberación" para la "esperanza" y la filosofía intercultural. Cuáles son sus alcances y apuestas.}

Primero la pedagogía de Freire que tiene esa raigambre latinoamericana, brasilera, y esa idea de la educación como un instrumento no para el "progreso" social, pero también está la idea de la interculturalidad, de que la educación en general es un proyecto europeo, un proyecto moderno; y decíamos que, en América latina, además de Europa, hay una diversidad de culturas, de saberes de lenguas, que no podemos resignarlas al olvido y seguir con el mismo proceso de colonización, de etnocidio. Pensando, como decíamos, cómo nos ven a los latinoamericanos, que somos narcos, simples corruptos. No podemos seguir pensando que las minorías lingüísticas son ignorantes por no conocer la cultura europea. Sino todo lo contrario. Conocen su lengua, conocen su religión, conocen su costumbre, conocen su sabiduría. Creo que tenemos que partir de esa valorización y para valorizarnos a nosotros mismos como Latinoamérica, y a ver si podemos levantar un poco nuestra autoestima, tan deteriorada. Justamente por esta visión colonial que tenemos a veces en nosotros mismos. Nuestra diversidad cultural y étnica es un valor muy importante y tenemos que aprovecharlo. Si bien las lenguas europeas tienen un peso importante en la formación educativa, eso no quiere decir que no puedan dejar espacio a lenguas originarias. 


\section{Su quehacer se ha fundado y asimismo dedicado a la edu- cación intercultural. ¿Qué significa trabajar pedagógicamente con comunidades históricamente marginadas por la visión monocultural que sostiene a la Universidad como centro exclu- sivo y hegemónico de producción y legitimación del saber?}

Para mí ha sido una experiencia increíble. De lo mejor que yo he tenido como profesional. La Universidad en Chapecó es una universidad muy distinta, muy bien organizada. Hay algunos profesores que están comprometidos con los derechos de la población indígena de la región, que ha sido una población muy castigada. La colonización es relativamente reciente, y a pesar de todo se ha podido mantener ahí la población, pudo sobrevivir física y culturalmente. Hay un grupo de profesores comprometidos que está trabajando muy bien. No obstante, están los problemas de la relación de los estudiantes indígenas con la Universidad. Les costaba mucho ir a la universidad justamente porque este tipo de organización no tiene nada que ver con la aldea.

Además, si bien hay un grupo de profesores que están comprometidos, en general la visión de la sociedad sobre los indígenas es muy prejuiciosa. Entonces es un territorio hostil para muchos estudiantes indígenas. Había que tener mucha fortaleza interior, que algunos la tenían, pero también existía una deserción enorme. Este grupo de profesores invirtió la situación. Después de ver el fracaso de tratar de integrar a los indígenas a la Universidad, la Universidad va a la aldea a dictar los cursos. Entonces se modificó la relación. Antes $90 \%$ desertaban y un $10 \%$ podía concluirla. Ahora 90\% queda dentro, o sea termina la cursada después hay más o menos un 55\% la conclusión con todos los exámenes. Después de un $90 \%$ termina la cursada le quedan exámenes y van terminando por lo menos en esta última bocanada hay solamente una 
deserción del 10\%. Entre otras cosas porque se trabaja con beca, se trabaja con libros indígenas para que estimulen la concurrencia. En ese sentido fue muy exitoso y a pesar que falta muchísimo, se ha avanzado desde donde partió hasta donde llegó.

Estoy muy contento de trabajar ahí. Y la universidad también se interculturaliza con estos proyectos. Y además también tiene esto: cuando los estudiantes terminan el grado es como que ya se van familiarizando con los profesores, con la universidad, adquieren autoestima porque ya con un grado universitario es mucho más fácil ir a los posgrados, a las especializaciones que se dictan en la universidad, en la ciudad y en estos programas no hay tantos problemas de deserción. Entonces se tiende como un puente en donde antes había una brecha enorme. Es muy interesante la experiencia.

\section{Producto del trabajo de los profesores, que están entre el espacio Universitario y las comunidades indígenas ¿Cómo funciona ese aspecto puntual de la traducción intercultural?}

Bueno esto también es difícil. Ahora publicamos con una profesora indígena, un texto que se titula "PROPUESTA INTERCULTURAL Y METODOLOGÍA INTERCULTURAL PARA LA PEDAGOGÍA INDÍGENA" en la Revista Brasilera de Estudios Pedagógicos. Esto surge porque no hay una pedagogía intercultural. Se habla mucho de interculturalidad, pero no hay ni una práctica porque esto es bastante novedoso. Hay muchas experiencias empíricas. Entonces tratamos de sistematizar eso. Salirse del modelo de escuela cuesta mucho, teniendo en cuenta que es muy de occidente. Para enseñar a las comunidades indígenas hay que tener en cuenta su cuerpo de conocimientos. Tienen sabidurías orales, tienen modos de saber-hacer. Saben hacer cosas, pero no tienen una teo- 
ría para aprehenderlo. Sin un modo de transmisión empírico, más que teórico, entonces es todo un trabajo más arduo. Se van dando pasos y cuanto más sensible es el profesor, cuanta más empatía tiene hacia los saberes es mucho más fácil.

Pero también hay muchos profesores que no quieren sino dictar su materia como ellos la dan en la otra universidad para no bajar el nivel, entonces creen que adaptando su materia a ese nuevo contexto están haciendo algo que baja la calidad del conocimiento. Mi idea es que el beneficio no es solamente de ese cuerpo de conocimientos nuevos, sino lo que se obtiene cuando es traducido e intercambiado entre contextos.

Es difícil ese dialogo, no solo entre personas sino entre saberes, entre culturas, entre lenguas. Los profesores hablan en portugués, y se dicta en portugués la licenciatura, a excepción de algunas materias sobre lengua y cultura indígena que la dictan profesores indígenas. Pero en general hay mucha más interculturalidad, o experiencia intercultural del lado de los indígenas porque hace 200 o 300 años que están lidiando con otra cultura y hay una experiencia, hay como un analfabetismo cultural más del lado de los profesores y de la sociedad no indígena, porque en general tendemos a imponer nuestra cultura en vez de aprender de la otra. Y los indígenas, por necesidad, tienen aprender de la otra cultura, por lo que acumulan bastante experiencia intercultural. Pero el proceso de traducción es un proceso práctico. Estamos escribiendo artículos para formalizar esa experiencia, pero hay pocos. Pocos, pero estamos en ese camino. 


\section{Según su experiencia y perspectiva, qué pueden decir Dussel y Freire a la formación y la reflexión jurídica.}

Hay un jurista y sociólogo colombiano con el que he compartido, Rosembert Ariza, que tiene mucha más experiencia que yo en eso, pero él estaba trabajando en un sistema jurídico de comunidades andinas y allá la perspectiva es muy diferente. Muchas veces no hay un sistema jurídico si no está descentralizado de la comunidad; hay como una cuestión de reestablecer la armonía y las normas jurídicas. Entonces, dentro de las comunidades las nociones y conceptos del derecho son bastante diferentes a los significados que le atribuimos nosotros. Así que ahí hay un buen trabajo para hacer. Pero enfocándose en el discurso formal jurídico, sus alcances y limitaciones. Aunque ya desde hace algunos años está el nuevo constitucionalismo latinoamericano que es bastante interesante como movimiento, que tiende a ser receptivo a estas preguntas sobre la plurinacionalidad, plurilingüismo y el espacio para otros sistemas jurídicos dentro de ciertas nacionalidades o ciertas conformaciones culturales. Creo que hay mucho por aprender ahí, mucho para trabajar también. Rosembert tiene un trabajo interesante, que recomiendo revisar, tanto en Brasil como en Bolivia. Me pareció una persona muy interesante y creo que hay mucho espectro para desarrollar ahí. También para trabajar y formar jueces u operadores del derecho, operadores judiciales que puedan incorporar esa perspectiva. Como ahora también se está incorporando la perspectiva de género que también es tan interesante para el derecho, la perspectiva intercultural no creo que sea menos interesante. Hay mucho por aprender ahí. 